\title{
LABORATORY SIMULATIONS OF GLACIAL ABRASION: COMPARISON WITH THEORY
}

\author{
By NeAl R. IVERSON \\ (Department of Geology and Geophysics, University of Minnesota, Minneapolis, Minnesota 55455,
}

\begin{abstract}
Glacial abrasion was simulated in experiments in which a small artificial glacier bed was pushed beneath a fixed ice block under pressure. The experiments provide a means of testing theoretical models of abrasion, particularly those factors that govern the magnitude of stress concentrations beneath abrading rock fragments. In preliminary experiments, vertical ice flow around a sphere mounted on the bed was studied. In subsequent experiments, marble tablets were pushed beneath granitic rock fragments frozen into the base of the ice block. Unlike previous abrasion experiments, the sliding velocity was realistic $\left(25 \mathrm{~mm} \mathrm{~d}^{-1}\right)$, and ice near the bed was at the pressure-melting temperature. Resultant striations closely resemble those observed on glaciated bedrock.

As predicted by Hallet (1979), the component of the ice velocity towards the bed strongly influenced stresses beneath fragments, and classical regelation and creep theory provided an approximate estimate of the downward drag force on fragments. Half of the rock fragments rotated significantly, accounting for $10-50 \%$ of their motion relative to the bed and influencing abrasion rates and the shear stress supported along the ice-bed interface. Striation patterns indirectly suggest that fragment rotations were inhibited by increases in ice pressure, which presumably increased the drag on roughness elements on fragment surfaces. This may have resulted from a reduction in the thickness of the water film around fragments, facilitated by leakage of water from the bed.
\end{abstract}

\section{INTRODUCTION}

Abrasion of bedrock by rock fragments embedded in the basal ice of sliding glaciers is the most throughly studied mechanism of glacial erosion (Chamberlin, 1888; Gilbert, 1910; Carol, 1947; McCall, 1960; Lister and others, 1968; Röthlisberger, 1968; Boulton, 1974, 1979; Hallet, 1979, 1981, paper in preparation; Mathews, 1979; Shoemaker, 1988). Recent work has been focused on developing theoretical models of abrasion by temperate glaciers (Boulton, 1974; Hallet, 1979, paper in preparation; Shoemaker, 1988). These models seek to delineate precisely the roles that different glaciological parameters play in the abrasion process.

Unfortunately, few data have been collected in field or laboratory studies, so abrasion models remain untested. Field studies (Boulton, 1974; Boulton and others, 1979; Anderson and others, 1982), hampered by the inaccessibility of glacier beds and the logistical difficulty of measuring important parameters in the subglacial environment, have provided insufficient information to evaluate theoretical predictions. Boulton and others (1979) successfully measured fragment-bed contact stresses beneath Glacier d'Argentière, but did not measure the rate of ice convergence toward the bed, a critical variable in most models of abrasion and debris-influenced basal drag (Hallet, 1979, 1981, paper in preparation; Shoemaker, 1986, 1988). In laboratory simulations of abrasion (Lister and others, 1968; Mathews, 1979), neither fragment-bed contact stresses nor rates of ice convergence toward the bed were measured. In addition, sliding velocities were unrealistically high, and ice temperatures were at least $16^{\circ} \mathrm{C}$ below the pressure-melting temperature.

The lack of empirical data complementing theoretical models leaves significant questions about the abrasion process unanswered. Considerable discussion has been focused on accurately assessing stresses between rock fragments and the bed (Boulton 1974; Hallet, 1979, 1981, paper in preparation; Shoemaker, 1988). Hallet (1979), in his pioneering work, recognized that the drag ice exerts on rock fragments as it flows toward the bed should strongly influence fragment-bed stresses. Although ice flow by regelation and creep around an isolated sphere has been analyzed by Watts (unpublished), the drag force on fragments abrading the bed may differ significantly from that predicted by standard regelation and creep theory. Drake and Shreve (1973) studied the motion of wires forced through temperate ice and found, due to the accumulation of solutes in the rear of the wires, that standard regelation theory overestimated the speeds of poorly conductive wires by one to two orders of magnitude at driving stresses below $0.1 \mathrm{MPa}$. Therefore, although there may be large differences between wire regelation and regelation around abrading fragments, drag forces on small fragments may be several orders of magnitude larger than those predicted by standard theory. In addition, the close proximity of the glacier bed should affect creep of ice around fragments (Hallet, 1981) and may cause incomplete refreezing beneath fragments (Morris, 1979). Friction at the contacts between fragments and the bed should produce heat that may also inhibit refreezing (Shoemaker, 1988). Resultant water-filled cavities beneath fragments may render fragment-bed contact forces dependent on the local hydrologic environment. The large uncertainty in estimating fragment-bed contact forces is a primary motivation for this study.

Effects of certain idealizations in abrasion models have not been tested. Although rock-fragment rotations are ignored in abrasion models, repetitive striation geometries on glaciated bedrock suggest that rotation of fragments is sometimes common. Effects of fragment rotations on abrasion rates and the debris-influenced component of basal shear stress may be significant. The angularity and dense packing of some rock fragments in basal ice are additional sources of uncertainty in abrasion models, which idealize rock fragments as smooth, isolated spheres.

In this paper, laboratory experiments are described that provide insight into these problems. An apparatus designed to slide an artificial glacier bed beneath a fixed block of ice was used to study abrasion. In preliminary experiments, vertical ice flow around a concrete sphere fastened to the bed was studied, and the resultant force between the sphere and the bed was measured directly. In subsequent experiments, abrasion was simulated by sliding smooth marble tablets beneath different concentrations of rock 
fragments incorporated into the base of the ice block, while the shear stress supported along the ice-bed interface was continuously monitored. The ice pressure and sliding velocity were appropriate for valley glaciers. Temperatures in the ice were within a few hundredths of a degree of the pressure-melting temperature, and the ice velocity toward the bed was monitored continuously and varied through a range of realistic values. Rotations of individual rock fragments occurred, and striations that were produced closely resemble those observed on glaciated bedrock.

These experiments are thought to be fairly representative simulations of abrasion occurring beneath glaciers. Several noteworthy differences between the experimental conditions and the expected conditions at the bed of a temperate glacier do exist and are discussed below. Although they impart some ambiguity to the interpretation of the results, they are relatively minor differences and do not obfuscate the general conclusions reached here or the relevancy of the results to existing abrasion theories.

\section{EXPERIMENTAL APPARATUS}

The experiments were conducted in a walk-in freezer with the apparatus shown in Figure 1 and described previously by Hooke and Iverson (1985). An ice block $(0.45 \mathrm{~m}$ by $0.20 \mathrm{~m}$ by $0.20 \mathrm{~m})$ is contained within a foursided steel box that is open on the bottom to accommodate artificial beds made of concrete or any other suitable material. The bed sits in a moveable steel carriage that is pushed forward by a screw attached to a geared-down electric motor. A pressure plate, driven by an air cylinder, fits snugly into the top of the box and forces the ice against the bed under a maximum pressure of $1.5 \mathrm{MPa}$. The pressure is measured with a load cell and recorded on a chart recorder. The total downward movement of the pressure plate during experiments is always approximately equal to the thickness of ice melted from the base of the ice block, suggesting that little deformation occurs in the ice, except locally where ice may creep around clasts. Therefore, the ice pressure is very nearly hydrostatic.

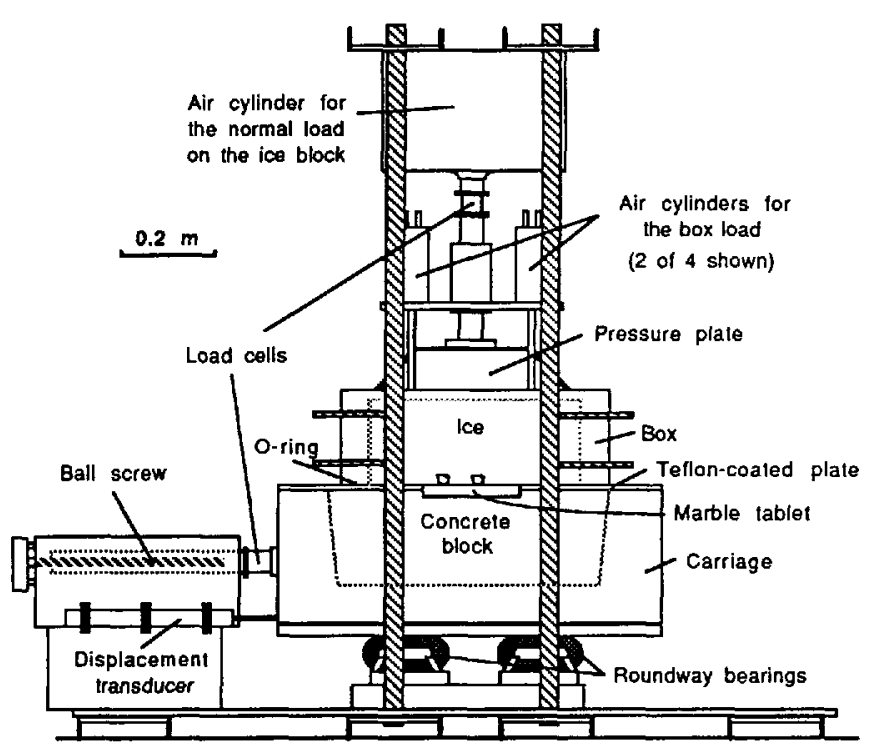

Fig. 1. Side view of the apparatus.

Downward movement of the pressure plate is measured to the nearest $0.005 \mathrm{~mm}$ with a dial micrometer. The total thickness of ice melted from the base of the ice block is measured at the conclusion of an experiment from thin toothpick-sized graduated wooden markers that are initially frozen vertically into the ice with their bottoms in contact with the bed. As melting at the base of the ice block occurs, they are either ground away by the bed or deflected laterally. In either case, the total amount of melting can be determined to the nearest $0.5 \mathrm{~mm}$. A $10 \mathrm{~mm}$ thick, teflon-coated steel plate separates the base of the box from the carriage. The base of the box is finely polished with a recess around its perimeter that contains an O-ring.
Four smaller air cylinders press the box against the teflon-coated plate. The goal here is to reduce the rate of water leakage from around the base of the box in order to minimize pressure gradients in the water film along the ice-bed interface.

The freezer is kept at a temperature of about $-4^{\circ} \mathrm{C}$, and the apparatus is insulated with foam rubber. The temperature within the bed and ice is controlled by heated oil that circulates through the apparatus. The oil enters the pressure plate first and then circulates through the walls of the box, and finally through the sides and bottom of the carriage. Six thermistors sense the oil temperature and turn on heaters mounted in the pressure plate, the box, and the carriage when the temperature falls below a pre-set value (Morgan, 1979). Additional thermistors are placed in the bed and ice and monitored periodically with a Fluke digital multimeter. The temperatures are accurate to $\pm 0.01{ }^{\circ} \mathrm{C}$.

In preliminary experiments, a concrete sphere, $53 \mathrm{~mm}$ in diameter, was fitted on to a hollow stainless steel rod that screwed into a concrete bed (Fig. 2). Ice motion past a concrete sphere of this size should be accommodated primarily by regelation. A larger sphere could not be used due to possible boundary effects from the walls of the box. Wires from thermistors in the sphere ran through the rod and out of the carriage. In order to measure the downward force on the sphere, two strain gauges were mounted longitudinally on the rod, $180^{\circ}$ from each other. They were calibrated by loading the rod with lead weights of different sizes. Forces on the rod were accurate to within $15 \mathrm{~N}$. The bed was kept stationary in these experiments while the vertical ice velocity was varied by changing the melt rate at the bed.

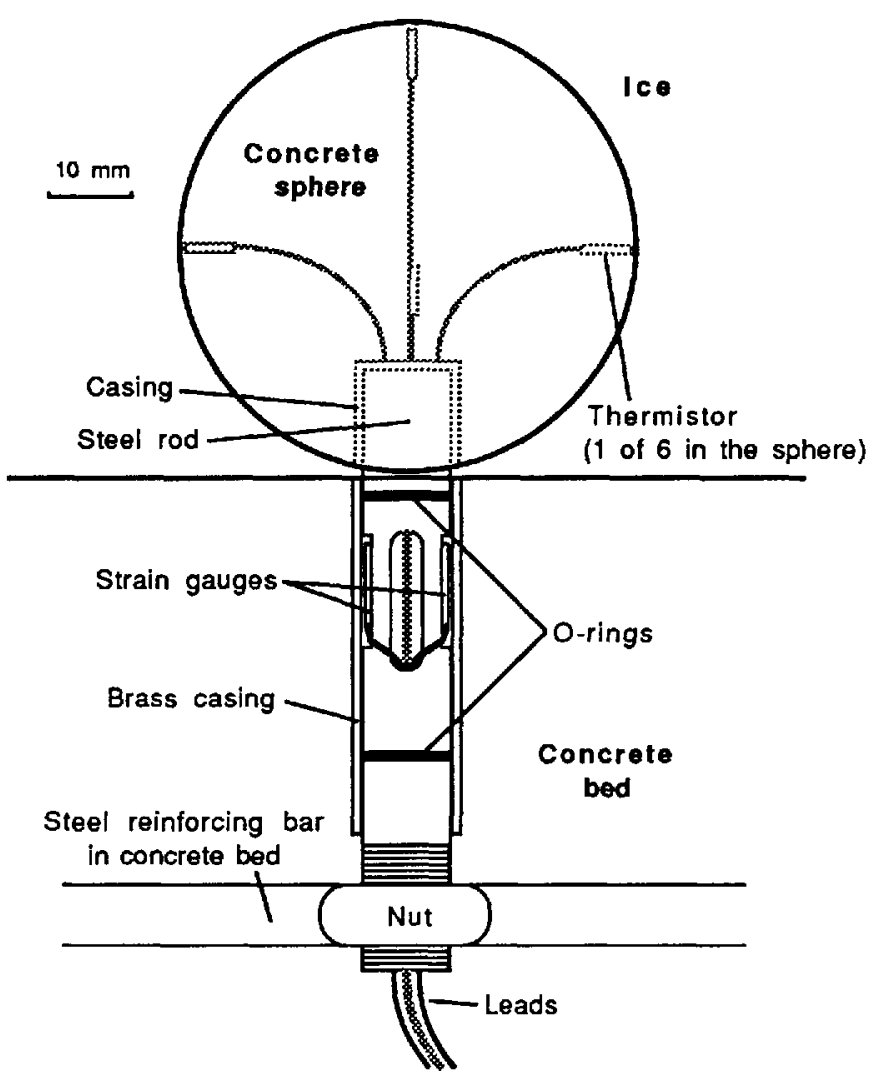

Fig. 2. Concrete sphere and strain-gauge assembly.

In the abrasion simulations, marble tablets $(0.25 \mathrm{~m}$ by $0.20 \mathrm{~m}$ by $0.02 \mathrm{~m}$ ) were inset into another concrete bed with their upper surfaces flush with the teflon-coated steel plate. During an experiment, the carriage was pushed beneath the ice at a speed of $25.4 \mathrm{~mm} \mathrm{~d}^{-1}$. The shear stress supported along the bed was measured with a load cell to $\pm 110 \mathrm{~Pa}$. Displacement of the carriage was measured with a position transducer.

\section{EXPERIMENTAL TECHNIQUE}

The first phase in these experiments is the preparation 
of the artificial bed. In the experiments with the concrete sphere, the bed is sealed with a thin layer of bar-top varnish, and the sphere is sealed with a thin layer of epoxy resin. In addition, the cracks between the bed and the teflon-coated steel plate are sealed with silicone rubber. In the abrasion simulations, tablets are fashioned out of slabs consisting of homogeneous, fine- to medium-grained marble and positioned tightly in the concrete bed. Any cracks between the tablets and the surrounding steel plate are filled with modeling clay and sealed with silicone rubber.

After the bed is prepared, the box is placed on the carriage in the position it will have at the initiation of the experiment, and the ice block is constructed. Distilled water is poured into the box, forming an ice layer a few millimeters thick that serves to hold the box in place. A second increment of water is then added, forming another layer of ice about $5 \mathrm{~mm}$ thick. At this point in the abrasion simulations, rock fragments are warmed slightly with a heat gun, placed on the ice layer, and allowed to melt downward to within $2-3 \mathrm{~mm}$ of the bed. Thus, at the beginning of each experiment the shear stress in the absence of fragment-bed friction could be determined before the fragments impacted the bed as a result of basal melting. Red lines parallel to the bed are painted on the fragments to facilitate measuring their total rotation at the end of the experiment. In addition, between two and four thermistors are frozen into the ice against the bed in order to record the temperature along the ice-bed interface. Finally, the graduated wooden melt indicators are frozen vertically in place against the bed.

After instrumenting the basal ice, subsequent layers of ice are added to the block in about $15 \mathrm{~mm}$ increments, allowing each layer to freeze completely before the next is added. This minimizes buckling of the ice due to its expansion upon freezing. Two or three additional thermistors are frozen into the ice at higher levels as the block is built. In some experiments, crystals of potassium permanganate dye are frozen into the ice directly above the rock fragments in order to trace water movement. In addition, parallel strands of flexible plastic about $1 \mathrm{~mm}$ in diameter, which function as passive strain markers, are sometimes placed in the ice above rock fragments to indicate qualitatively the amount of ice deformation that occurs around fragments as ice melts at the bed. In experiments with the concrete sphere, grids of threads are frozen into the ice directly above the sphere for the same reason.

Granitic rock fragments, with mean radii between 15 and $20 \mathrm{~mm}$, were used in the abrasion experiments. The large hardness contrast between the fragments and the bed amplified some of the effects the experiments were designed to measure. Three abrasion experiments lasting between 4 and $5 \mathrm{~d}$ were conducted. In two of these experiments, isolated rock fragments were frozen into the ice whereas, in the third, fragments were closely spaced with adjacent fragments in contact with each other. Rock fragments with numerous angularities but relatively high sphericity were chosen (Fig. 3). Smooth, spherical rock fragments would have allowed a more direct comparison with existing theory (Hallet, 1979, 1981) but, if there had been negligible friction between the ice and the spheres, as is assumed in theory, they would have rotated easily in the ice, resulting in little abrasion.

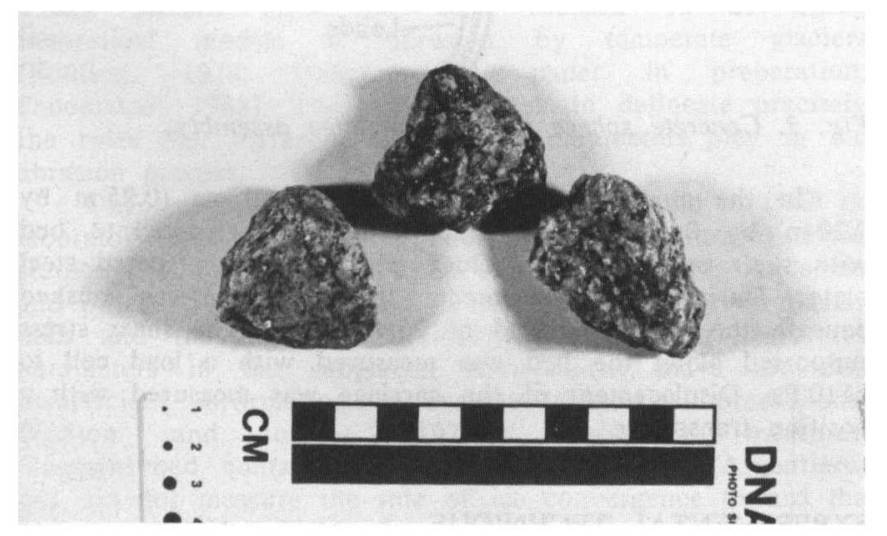

Fig. 3. Three representative rock fragments from the abrasion experiments.
To start an experiment, the oil-circulation pump and heaters are turned on, and the pressure plate is lowered on to the ice block. As pressures are initially increased on the ice block, the pressure plate moves a fraction of a millimeter, presumably due to compression of air in the ice. Over the next several days, temperatures in the apparatus are slowly raised by adjusting the temperature at which the thermistors turn on the heaters, until melting occurs at the bed. This becomes apparent when thermistors in the basal ice record temperatures commensurate with the applied pressure and further increases in heat supplied to the bed do not change the basal ice temperature. At the same time, the pressure plate begins to move downward.

In experiments with the concrete sphere, the carriage is held stationary, while the downward vertical ice velocity is varied by changing the melt rate at the bed; resultant changes in the downward force on the sphere are recorded. Changes in the basal melt rate are accomplished by adjusting the settings of the heaters mounted in the carriage. In the abrasion simulations, the motor driving the ball screw is turned on at the inception of melting, and the carriage begins sliding beneath the box. The shear stress in the absence of fragment-bed friction was different in each experiment and ranged from 4.7 to $24.4 \mathrm{kPa}$. After fragments were in contact with the bed, the vertical ice velocity and normal load on the ice block were periodically changed in order to assess the relationship between these variables and the shear stress.

Vertical ice velocities ranged from 0 to $2500 \mathrm{~mm} \mathrm{a}^{-1}$. Normal geothermal heating of a temperate glacier will only be sufficient to induce ice velacities normal to the bed of about $10 \mathrm{~mm} \mathrm{a}^{-1}$. However, as noted by Hallet (1979), local rates of ice convergence toward the bed that are several orders of magnitude larger than this are likely along stoss surfaces where abrasion is most pronounced. Pressure on the ice block ranged from 0.4 to $1.0 \mathrm{MPa}$. These are equivalent to mean ice pressures beneath glaciers that are 45 and $113 \mathrm{~m}$ thick, respectively.

Movement of the pressure plate is used as a measure of the vertical ice velocity. This requires that negligible melting occurs beneath the pressure plate along the upper surface of the ice block. To insure that this is the case, heaters are adjusted so that most of the heat that is conducted to the ice block comes from the bed and the walls of the box, rather than from the pressure plate. Measurements of the total amount of basal melting from the graduated wooden markers at the conclusion of the experiments showed that, in all cases, over $92 \%$ of the pressure-plate movement was due to basal melting. Unfortunately, supplying more heat to the ice from the bed than from the pressure plate led to small but undesirable vertical temperature gradients in the ice that are discussed later in this section.

At the conclusion of the experiments with the concrete sphere, the pressure plate is raised, and the ice block is lifted a few millimeters off the bed to allow any water present to drain from around the sphere. Next, the box is removed from the ice block, and the block is refrozen and dissected in place. This is necessary because the instrumentation in the sphere is joined to the bed. At the conclusion of the abrasion experiments, the displacement screw is turned off, the pressure plate is lifted, the braces holding the box in place are removed, and the box and ice block are quickly lifted from the carriage, exposing the base of the ice block and the abraded marble tablets. The total horizontal displacement of the bed relative to the ice at the conclusion of the experiments ranged from 96 to $127 \mathrm{~mm}$. The base of the ice block and the striations are then photographed, and a number of measurements and observations are made, including the size and geometry of any cavities in the ice, the rotation of rock fragments, the deformation of strain markers, the distribution of dye, and the erosion and deflection of the wooden melt indicators.

The temperature distribution in the ice and bed during the experiments differed slightly from the expected temperature distribution in a small block of ice at the bed of a temperate glacier. In the absence of bedrock irregularities, temperatures should be essentially uniform and equal to the pressure-melting temperature; all heat conducted to the bed of the glacier should melt ice. In these experiments, ice at the bed was at the pressure-melting 


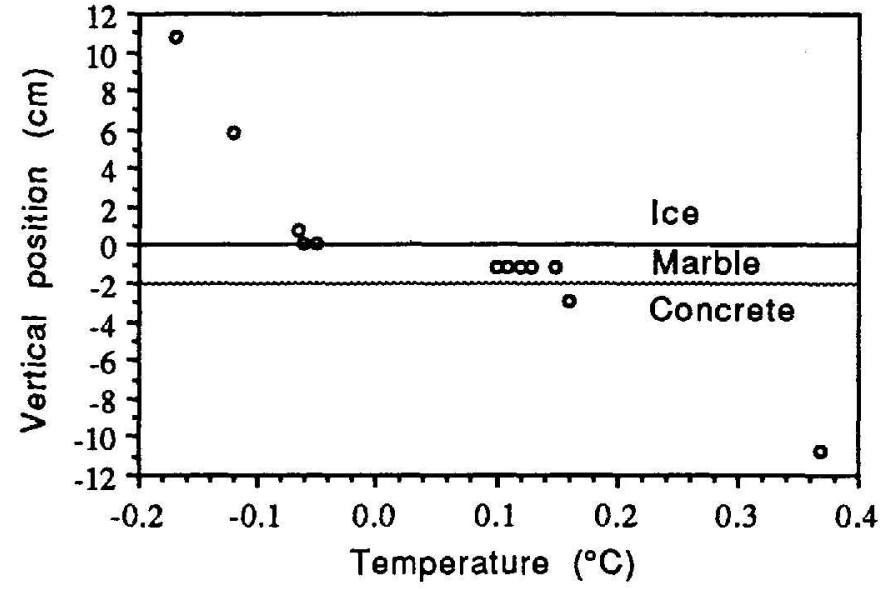

Fig. 4. Temperatures at thermistor positions in the ice and bed during one of the abrasion experiments. The temperature distribution is typical of all of the experiments. Different temperatures at a specific depth reflect horizontal temperature differences. The pressure on the ice block was $0.95 \mathrm{MPa}$, and temperatures at the bed were about $-0.06^{\circ} \mathrm{C}$, which is within $0.01^{\circ} \mathrm{C}$ of Harrison's (1972) value for the lowering of the melting temperature of ice per unit pressure, $0.074^{\circ} \mathrm{CMPa}^{-1}$.

temperature, but temperatures higher in the ice block were slightly colder (Fig. 4), suggesting that heat was being conducted vertically upward through the ice block. Thus, basal melting accurred only when heat flow through the bed to the ice-bed interface exceeded heat flow upward into the ice. Therefore, to produce a given basal melt rate, the mean temperature gradient in the bed had to be increased beyond levels that are reasonable for temperate glaciers (Fig. 4). A possibly more serious problem is the effect of the small


the character of the ice flow around the sphere and the rock fragments. Ice locally frozen on to the sphere or rock fragments would significantly influence the downward force they exert on the bed. Whether or not this occurred will be evaluated in conjunction with the results.

A second deviation from natural conditions is the large pressure gradient that probably existed in the water film along the surfaces of the rock fragments and the bed. In the experiments with the sphere, most of the water produced by basal melting leaked out of the system mainly from around the pressure plate, and in the abrasion experiments water apparently leaked through the bed around the marble tablets. Water in the film was therefore hydraulically connected to water in close proximity that was at atmospheric pressure. The average water-pressure gradient along the bed was about $10 \mathrm{MPa} \mathrm{m}^{-1}$, the ice pressure divided by half the width of the bed. In the vicinity of the sphere and fragments, this is probably an overestimate because the majority of the reduction in pressure is likely to have occurred near the $O$-ring around the pressure plate and near the seal around the marble tablets. Nevertheless, water-pressure gradients along the bed were probably larger than those expected beneath temperate glaciers. Possible exceptions would be along parts of glacier beds that are near cavities in the lees of obstacles or near subglacial conduits where water pressures may sometimes be atmospheric (Hooke, 1984).

\section{RESULTS}

\section{Post-experimental measurements and observations}

At the conclusion of the experiments, examination of the bases of the ice blocks provided information about the mode of ice flow around the sphere and rock fragments. Three experiments with the concrete sphere were performed. Unfortunately, in two of these experiments the strain gauges malfunctioned, and the downward force on the sphere is unknown. Therefore, although some useful information about the temperature distribution in the bed was gathered in these experiments, the following discussion is focused on the results of the third experiment with the sphere (S1) and the three abrasion experiments (A1, A2, A3). Information associated with them is listed in Table I.
TABLE I. GENERAL INFORMATION ABOUT THE EXPERIMENTS

\section{Experiments}

\begin{tabular}{|c|c|c|c|c|}
\hline & SI & $A I$ & $A 2$ & $A 3$ \\
\hline Duration (h) & 78.0 & 109.0 & 102.7 & 120.7 \\
\hline Bed displacement $(\mathrm{mm})$ & 0.00 & 95.8 & 108.8 & 127.5 \\
\hline Total basal melt (mm) & 2.1 & 8.9 & 10.3 & 14.0 \\
\hline Number of fragments & 1 & 3 & 5 & 8 \\
\hline $\begin{array}{l}\text { Mean fragment } \\
\text { radius }(\mathrm{mm})\end{array}$ & 26.5 & 17.0 & 16.0 & 17.0 \\
\hline $\begin{array}{l}\text { Number of fragments } \\
\text { that rotated more that } \\
10^{\circ}\end{array}$ & - & 2 & 1 & 5 \\
\hline $\begin{array}{l}\text { Number of cavities } \\
\text { Combined volume of } \\
\text { cavities }\left(\mathrm{mm}^{3}\right)\end{array}$ & 1 & 3600 & 6000 & 4800 \\
\hline
\end{tabular}

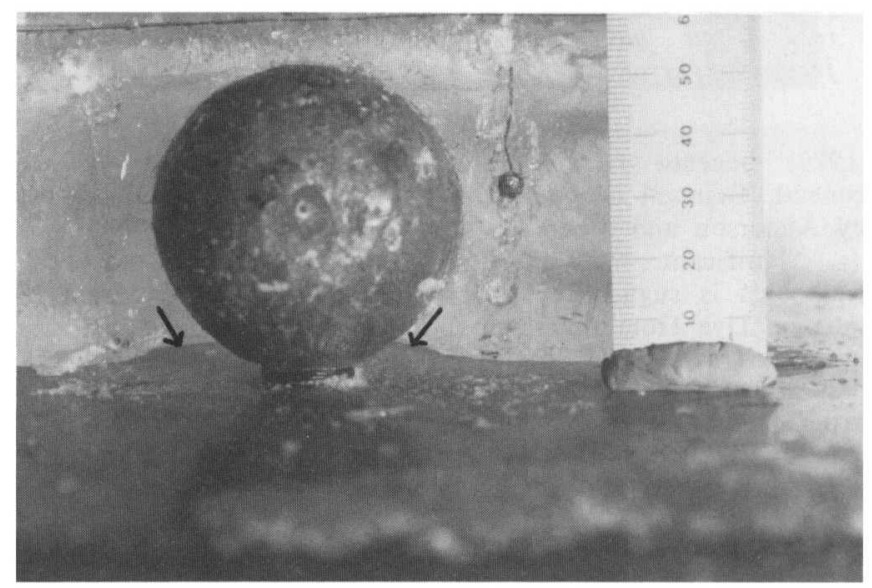

Fig. 5. Vertical cross-section of the cavity (arrows) that formed in experiment $S 1$. Ice has been cut away from half of the sphere, and to the sphere's right is a weighted thread that was intended to detect deformation, but deformed during construction of the ice block. There was no bed motion. Scale is graduated in millimeters.

Beneath the sphere in experiment Sl, a large radially symmetric cavity formed (Fig. 5) with a volume of $4300 \mathrm{~mm}^{3}$. The cavity has several possible origins. It may have been a product of vertical ice flow, representing the volume of ice melted along the upper half of the sphere that did not refreeze along its lower half. However, the cavity shape suggests that at least a fraction of the cavity volume was due to locally high melt rates beneath the sphere. Readings from thermistors showed that temperatures in the bed were warmer in the vicinity of the stainless-steel rod than elsewhere, suggesting that the rod focused heat on the bed below the sphere. The thermal conductivities of the rod and concrete were 45.2 and $1.1 \mathrm{~W} \mathrm{~m}^{-1}{ }^{\circ} \mathrm{C}^{-1}$, respectively

Although the cavity in experiments S1 may have been due in part to the presence of the rod, similar cavities formed beneath most of the rock fragments in the abrasion experiments. Cavities ranging in volume from 200 to $4000 \mathrm{~mm}^{3}$ formed beneath two of the three fragments in experiment A1, all five of the fragments in experiment $A 2$ (Fig. 6), and seven of the eight fragments in experiment A3. The cavities were skewed strongly toward the "downglacier" side of fragments and were largest in the lee of rock fragments that had rotated significantly. They were clearly the result of relative movement between the ice and the fragments, the movement having been accommodated by melting along fragment surfaces without subsequent refreezing. Refreezing was probably inhibited by heat flow from the bed and frictional heat generation at fragment-bed contacts. Frictional heat can be calculated from average fragment-bed shear stresses and fragment velocities, and can account for $7-13 \%$ of the total cavity volume, assuming that all frictional heat melted ice. Similar cavities in the lee of rock fragments have been observed by Boulton and others 


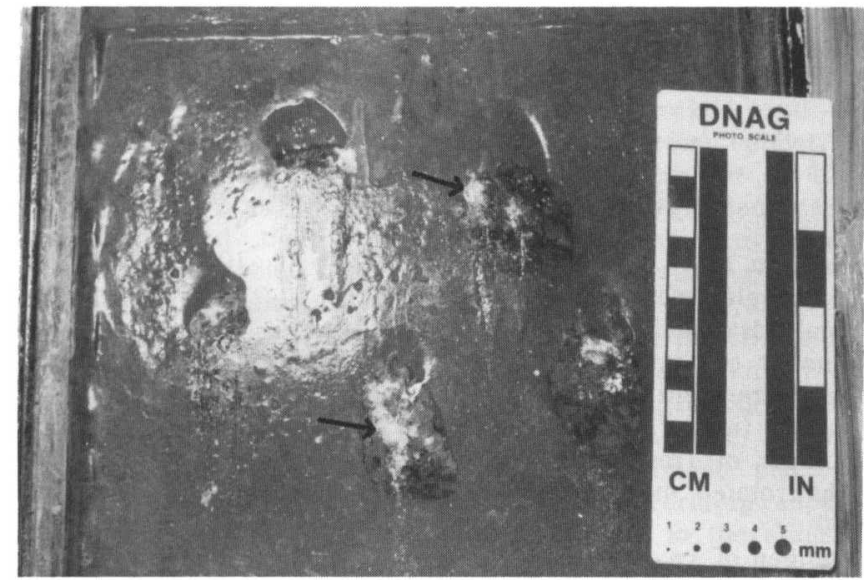

Fig. 6. Cavities that formed beneath the five rock fragments in experiment $A 2$. Ice motion relative to the bed was parallel to the scale from bottom to top. Note the white rock flour adhering to the striator points of each fragment (arrows).

(1979) beneath Glacier d'Argentiere and by the author beneath Grinnell Glacier in the ceiling of a cavity described by Anderson and others (1982).

Significant melting along the surface of the rock fragments is suggested by observations of dye movement in the ice. Dye from potassium permanganate crystals that were initially frozen into the ice about $2 \mathrm{~mm}$ above several of the rock fragments was observed at the end of the experiments in the ice at the bed, indicating that ice had melted above the fragments and that water flowed downward along the fragment surfaces to the ice-bed interface.

Strain markers indicate that there was little ice deformation. The grid of threads placed above the sphere in experiment Sl showed no sign of lateral displacement. Similarly, above one of the rock fragments in experiment A2, where the total downward ice movement was about $10.3 \mathrm{~mm}$, less than $1 \mathrm{~mm}$ of lateral displacement between two initially parallel strands of plastic was measured. This evidence, when considered along with the presence of the cavities and the mobility of the dye, suggests that ice motion around the sphere and rock fragments was accommodated primarily by melting rather than by creep. This is consistent with regelation and creep theory (Watts, unpublished), which suggests that regelation should be the dominant flow mechanism around concrete and rock spheres that have radii smaller than $0.10 \mathrm{~m}$. It also implies that,

TABLE II. FRAGMENT ROTATIONS AND THE FRACTION OF FRAGMENT DISPLACEMENT BY ROLLING DURING THE ABRASION EXPERIMENTS. FRAGMENT DISPLACEMENT BY ROLLING WAS CALCULATED BY ASSUMING THAT FRAGMENTS WERE SPHERES WITH RADII EQUAL TO THE MEAN RADII OF THE FRAGMENTS. RANGES OF VALUES FOR THE FRACTION OF DISPLACEMENT BY ROLLING RESULT FROM UNCERTAINTY IN THE AMOUNT OF DISPLACEMENT THAT OCCURRED WHILE FRAGMENTS WERE IN CONTACT WITH THE BED

\section{Experiment Fragment rotations}

Al

A2

A3

$\begin{array}{rr}35^{\circ} \pm 3^{\circ} & 0.11-0.14 \\ 31^{\circ} \pm 3^{\circ} & 0.12-0.17 \\ 50^{\circ} \pm 8^{\circ} & 0.12-0.21 \\ 25^{\circ} \pm 4^{\circ} & \\ 91^{\circ} \pm 5^{\circ} & 0.05-0.09 \\ 130^{\circ} \pm 5^{\circ} & 0.20-0.30 \\ 152^{\circ} \pm 8^{\circ} & 0.30-0.43 \\ 155^{\circ} \pm 10^{\circ} & 0.34-0.50 \\ & \end{array}$

although the ambient ice temperature several centimeters above the bed was a few hundredths of a degree below the pressure-melting temperature, the ice in the vicinity of the sphere and rock fragments was at the melting temperature.

Eight of the total of 16 rock fragments in the abrasion experiments rotated more than $10^{\circ}$, accounting for $10-50 \%$ of their motion relative to the bed (Table II). In experiment A3, four of the rock fragments rotated more than $90^{\circ}$. Even when rock fragments were initially placed so that several striator points on each fragment would impact the bed simultaneously, substantial rotations sometimes occurred. Points on rock fragments that had actively striated the bed could be easily identified due to rock flour that was, without exception, plastered on to their leading edges (Fig. 6). On some of the rock fragments that had rotated significantly, a series of flour-coated striator points was present along the circumference of the fragments, illustrating the progressive rotation of new striator points against the bed and their subsequent rotation of $f$ of the bed.

The striations produced in the abrasion experiments (Fig. 7a-d) closely resembled striations observed on glaciated bedrock. They ranged in size from faint discolorations of the polished tablets to ploughed grooves up to $2 \mathrm{~mm}$ deep. Partial ring fractures existed along the bottoms of most of the striations with their open ends facing "down-glacier" (Fig. 7b), consistent with field observations (Chamberlin, 1888; Iverson, unpublished). They were best developed on the marble tablet from experiment $A 3$, which was the finest-grained of those used, although there were numerous fractures of more irregular geometry at the bottoms of striations on the coarser-grained marble. No evidence of ductile deformation like that observed in the laboratory study of Scholz and Engelder (1976) was observed. Many of the striations that were ploughed by rotating fragments were discontinuous, reflecting the rotation of striator points on to and of $f$ of the bed (Fig. 7a, c). Small moraine-like ridges of rock were left at the ends of striations (Fig. 7d). The flour consisted mostly of angular calcite fragments ranging in size from microscopic fragments to thin sheet-like fragments up to $2.5 \mathrm{~mm}$ long. Present, but greatly subordinate in volume to the calcite fragments, were scattered pieces of feldspar and hornblende, indicating that some comminution of the granite striator points occurred.

\section{Effects of the ice velocity normal to the bed}

The downward force on the sphere during experiment S1 is plotted along with the vertical ice velocity in Figure $8 \mathrm{a}$. The normal load on the ice block was $0.95 \mathrm{MPa}$. An increase in force on the sphere of $145 \mathrm{~N}$ occurred when the normal load was applied to the ice block prior to hour 0 , before bringing the ice to the pressure-melting temperature. The expected increase in force is about $108 \mathrm{~N}$ (normal load multiplied by the area of the rod). The difference between the measured and expected value may be due to compression of the ice block. $145 \mathrm{~N}$ has been subtracted from the measured force on the sphere in order to isolate the drag on the sphere that resulted from downward ice flow. The dial micrometer on the pressure plate was read at intervals of $2-10 \mathrm{~h}$, so velocities are averaged over these intervals. At hour 69 , the micrometer jammed; the vertical ice velocity over the remaining $7 \mathrm{~h}$ of the experiment was determined by calculating the basal melt rate from the measured temperature distribution in the bed and ice.

A direct relationship between the vertical ice velocity and the force on the sphere is suggested. Changes in the velocity from hour 31 to hour 70 , and from hour 70 until the experiment's conclusion, produced roughly synchronous changes in force on the sphere. However, there is a lag of about $4 \mathrm{~h}$ between the initial increase in velocity at hour 0 and the resultant increase in force. Consistent with this lag, no vertical temperature gradient existed in the sphere until hour 4 of the experiment, suggesting that melting and ice movement near the sphere's surface was delayed relative to melting over most of the block's base.

The vertical ice velocity during the experiment is now used, together with regelation and creep theory, to calculate the expected drag force on the sphere. Because the buoyant weight of the sphere in ice is negligible, the normal force beneath it, $F_{\mathrm{N}}$, in excess of the mean ice pressure at the bed is equal to the drag force and is given by 

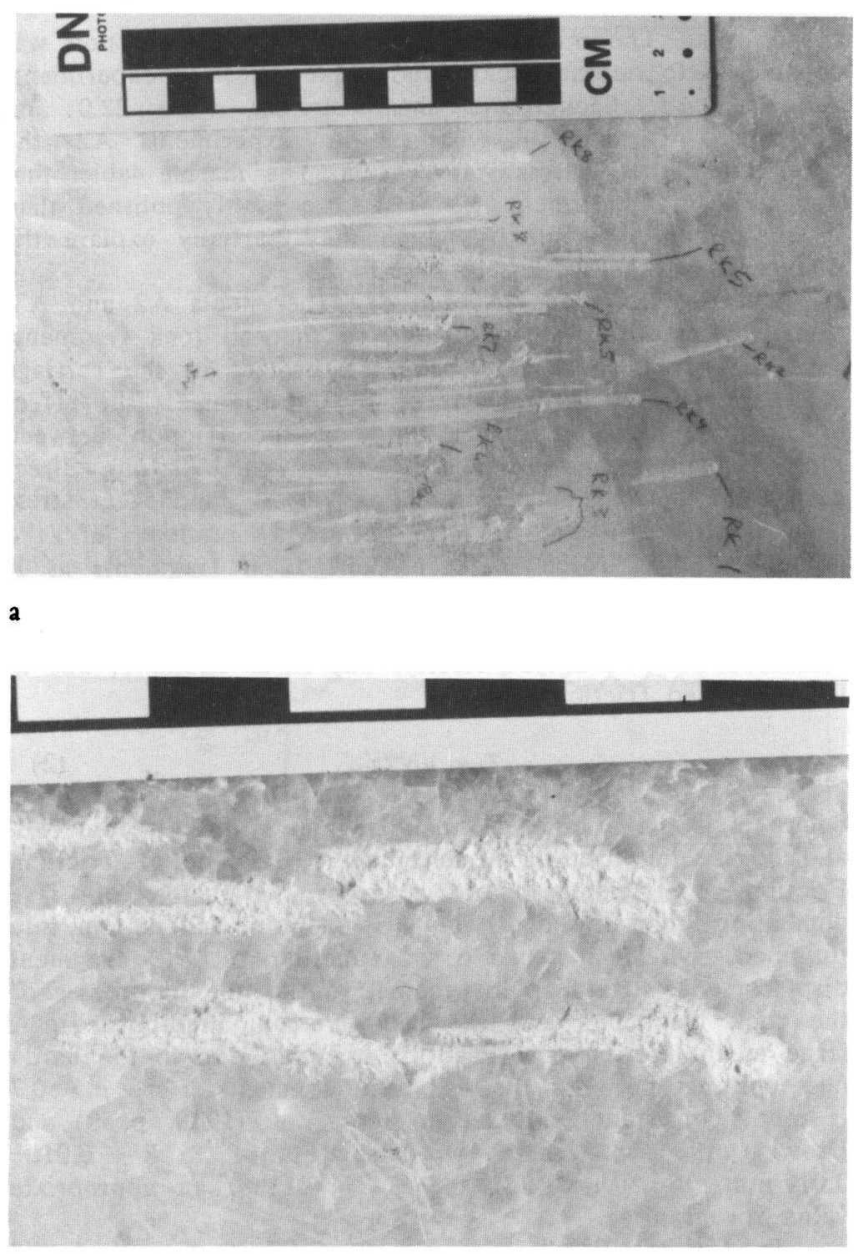

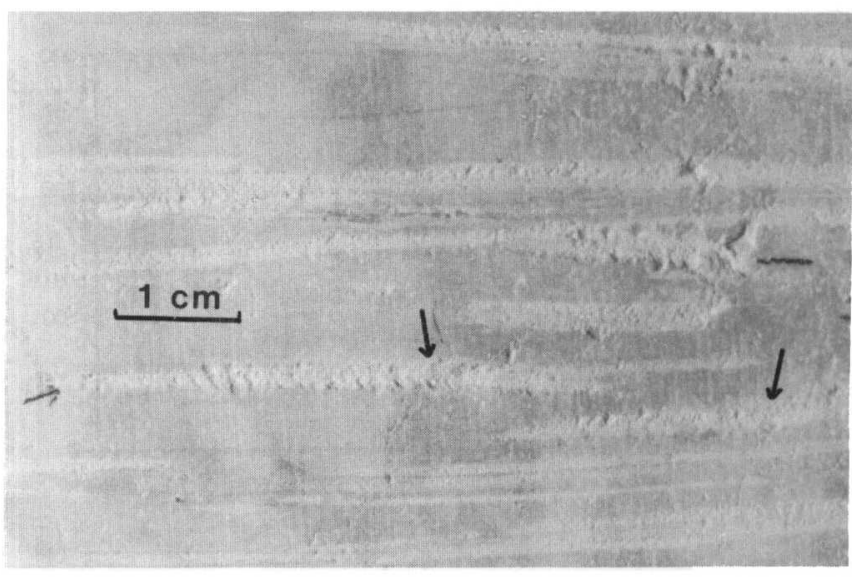

b
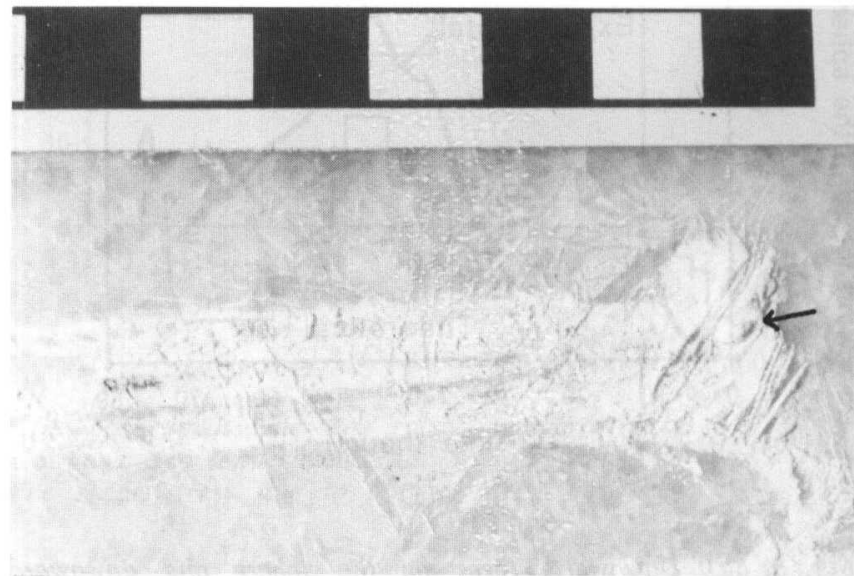

Fig. 7. (a) Striations from experiment A3. (b) Partial ring fractures (chattermarks) along the bottoms of striations from experiment $A 3$ (arrows). (c) Discontinuous striations produced by one rock fragment in experiment A2. (d) Accumulation of rock flour at the end of a striation from experiment A2 (arrow). Scales are graduated in centimeters, and the ice motion relative to the bed was from left to right.

$$
F_{\mathrm{N}}=\Psi V_{\mathrm{N}}
$$

where

$$
\Psi=\frac{4 \pi n R^{3}}{R_{*}^{2}+R^{2}}
$$

(Hallet, 1979). Here, $R$ is the sphere's radius, $R_{*}$ is the transition radius for concrete, and $n$ is the effective ice viscosity. In the experiment, $R=0.0265 \mathrm{~m}$ and $R *=$ $0.11 \mathrm{~m}$. The expression for the drag coefficient, $\Psi$, was derived by Watts (unpublished) for the steady-state motion of an isolated sphere through a linearly viscous, regelating fluid. In order to specify accurately a value for the effective ice viscosity, the effective shear stress in the vicinity of the sphere must be estimated. This is greatly complicated by the unknown amount of melting that occurred along the sphere's upper surface, which should strongly affect the local effective shear stress. Because of this difficulty, an effective ice viscosity consistent with other abrasion studies, 0.1 MPa a (Hallet, 1979; Shoemaker, 1988), is used, although this value is clearly uncertain. The uncertainty is further compounded by the possible influence of fabric (Lliboutry and Duval, 1985), and water content (Duval, 1977) on viscosity.

In Figure $8 \mathrm{~b}$, the theoretical and experimental drag forces on the sphere are plotted. With the exception of the period from hour 56 to hour 70 , the experimental force is underestimated by no more than a factor of two by the theory. The similarity of the experimental and theoretical values is surprising in the light of the aforementioned uncertainties and the fact that the regelation cycle was not complete. Melting occurred above the sphere, but refreezing beneath the sphere did not. Instead, as noted earlier, a water-filled cavity developed. Evidently, heat flow to the sphere's upper surface from the bed must have been approximately equal to that expected if the regelation cycle had been complete, thereby maintaining melt rates and normal stresses along the upper half of the sphere that were roughly similar to the theoretical prediction. The theoretical underestimate may have resulted from the water in the cavity exerting an upward pressure on the sphere that was less than the ice pressure expected beneath the sphere if refreezing had occurred. Alternatively, it may indicate that the effective ice viscosity was larger than that used in the calculation of $\psi$

A possible source of uncertainty in this comparison is that the ice velocity toward the bed may have varied too rapidly for heat flow through the sphere to reach a steady state. If the resistance to heat transfer at the surface of a sphere is small, the time necessary for the center of a sphere to approximately equilibrate with a change in temperature at its surface is equal to $R^{2} / \mathrm{k}$, where $\mathrm{k}$ is the thermal diffusivity (Wolf, 1983, p. 118). For concrete, $k$ ranges from $0.6 \times 10^{-6}$ to $1.0 \times 10^{-6} \mathrm{~m}^{2} \mathrm{~s}^{-1}$. Thus, the center of the sphere should have equilibrated to an external temperature change in a maximum of about $1200 \mathrm{~s}$, suggesting that over the intervals that vertical ice velocities were averaged, periods of one to several hours, application of the steady theory is appropriate.

In the abrasion experiments, the melt rate at the bed was changed periodically in order to assess the influence of the vertical ice velocity on shear stress. A part of the shear stress was due to drag that resulted from regelation of ice around microscopic roughness elements on the tablet surface. As noted earlier, this background shear stress was determined by freezing the rock fragments in place off the bed so that during the initial hours of the experiments there was no fragment-bed friction. 


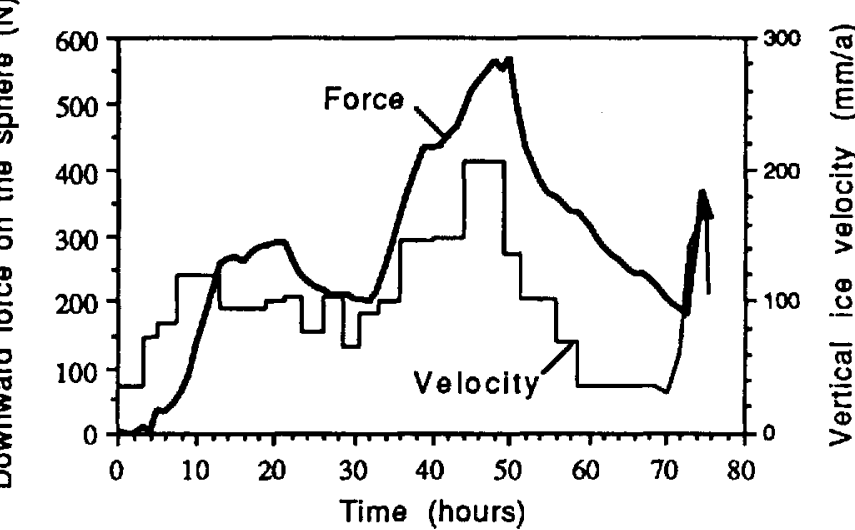

(a)

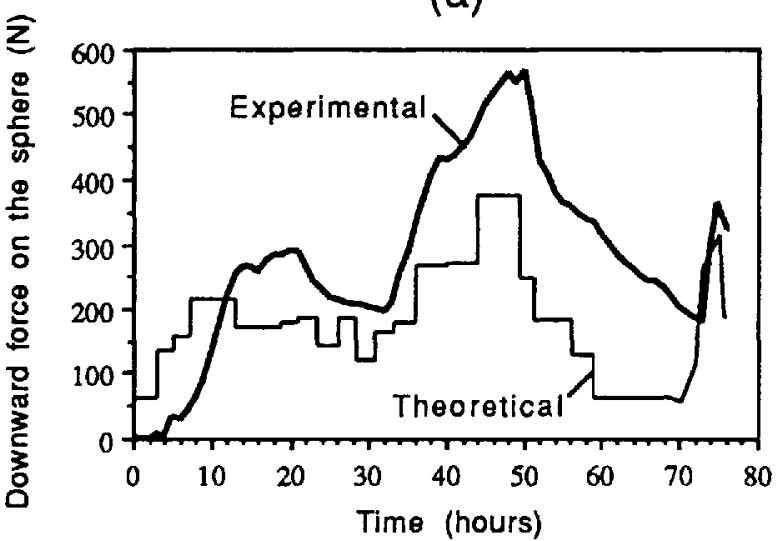

(b)

Fig. 8. (a) Downward force on the sphere and downward vertical ice velocity during experiment SI. (b) Downward force on the sphere and the theoretical drag force that was calculated with the vertical ice velocity using $n=0.1 \mathrm{MPa} a$

After bringing the ice at the bed to the pressuremelting temperature, the motor driving the ball screw was turned on. At first, the carriage did not move as the shear stress rapidly rose but, within $2 \mathrm{~h}$, displacement of the carriage would begin, followed by a small reduction in shear stress. The minimum reached after this reduction was considered to be the background shear stress. In experiments A1 and A3, background shear stresses were 22.0 and $24.5 \mathrm{kPa}$, respectively, whereas in experiment A2 the background shear stress was $4.7 \mathrm{kPa}$. The marble tablet that was used in experiment A2 was more highly polished than in the other experiments, which may partially explain the difference in shear stress.

On two occasions in each of experiments A2 and A3, after sufficient time had elapsed so that all rock fragments were in contact with the bed, the heaters in the carriage were set warmer for periods of $5-10 \mathrm{~h}$ to assess the effect of changing the basal melt rate on the friction between rock fragments and the bed. There was a strong direct correlation between the vertical ice velocity and shear stress (Fig. 9a-d). This must have been a product of the downward drag force that ice exerted on fragments as it flowed toward the bed.

The theoretical shear stress is now calculated from the measured downward ice velocity. The shear stress, $\tau$, due to fragment-bed friction is:

$$
\tau=\mu N \Psi V_{\mathbf{N}}
$$

where $N$ is the number of rock fragments abrading the bed, and $\mu$ is the mean fragment-bed coefficient of friction. Friction coefficients may vary by a factor of five depending upon the depth of striator point indentation into the bed, which in turn is a function of $F_{\mathrm{N}}$, fragment displacement, striator point geometry, and the hardnesses of the rock fragments and the bed (Iverson, unpublished). A large mean friction coefficient is expected due to the hardness contrast between the bed and fragments. Here $\mu=0.7$ is used, consistent with Jaeger and Cook (1979, p. 59) and Drewry $(1986$, p. 52). In the calculation of $\Psi, R=0.016-$ $0.017 \mathrm{~mm}, n=0.1 \mathrm{MPa}$ a, and $R_{*}=0.13 \mathrm{~m}$, an appropriate value for granite.

In Figure $10 \mathrm{a}-\mathrm{d}$, theoretical values of $\boldsymbol{T}$ are plotted for experiments $A 2$ and $A 3$. The background shear stress that was measured in each experiment has been subtracted from the total shear stress. In Figure $10 \mathrm{c}, N=5$ because only five of the eight rock fragments in experiment A3 produced striations over this time interval. This was determined by carefully measuring the lengths of the striation segments and assuming that fragments moved at a velocity equal to $90-100 \%$ of the ice sliding velocity relative to the bed. This is a reasonable approximation because the frictional retardation of relatively spherical fragments in ice should be roughly equal to the product of the average ice

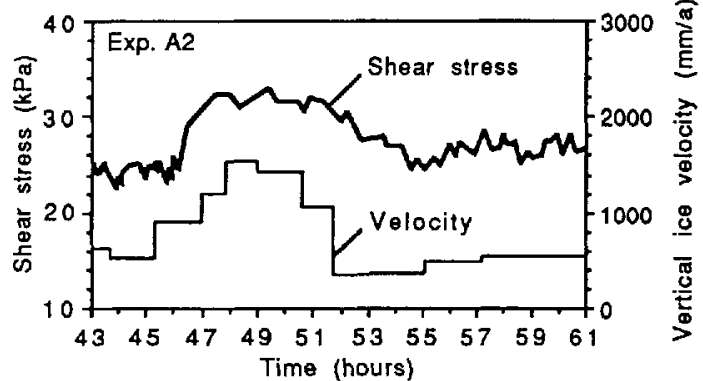

(a)

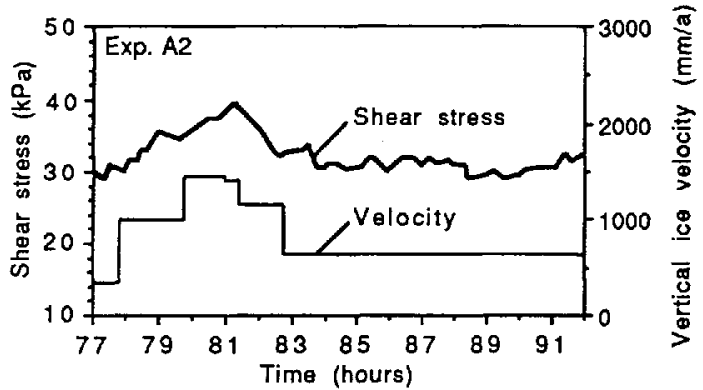

(b)

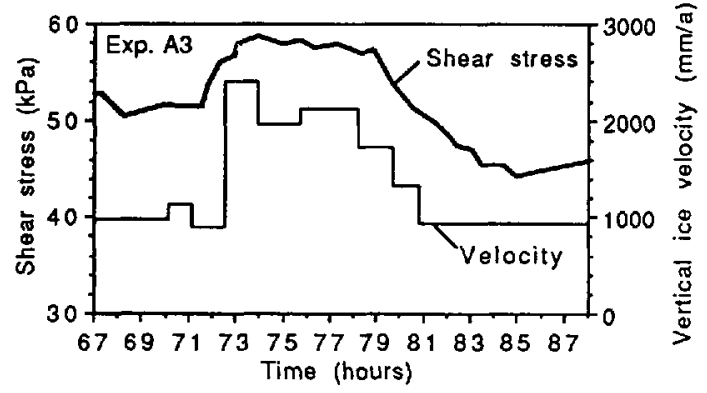

(c)

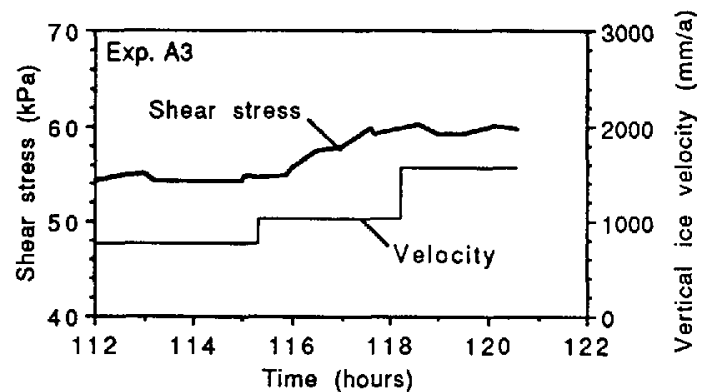

(d)

Fig. 9. Shear stress and verical ice velocity when the basal melt rate was raised temporarily in $(a, b)$ experiment $A 2$ and $(c, d)$ experiment $A 3$. 


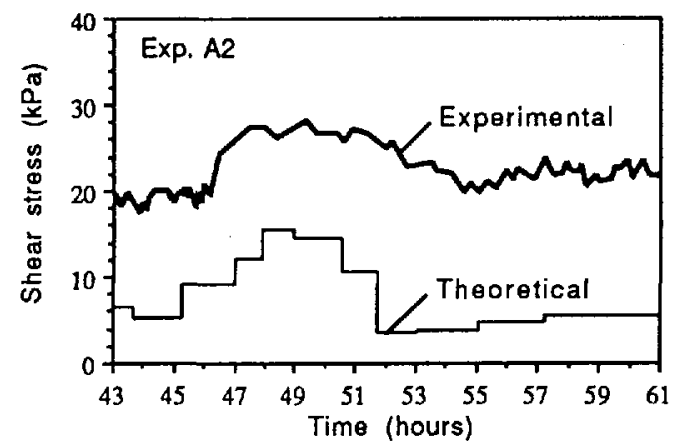

(a)

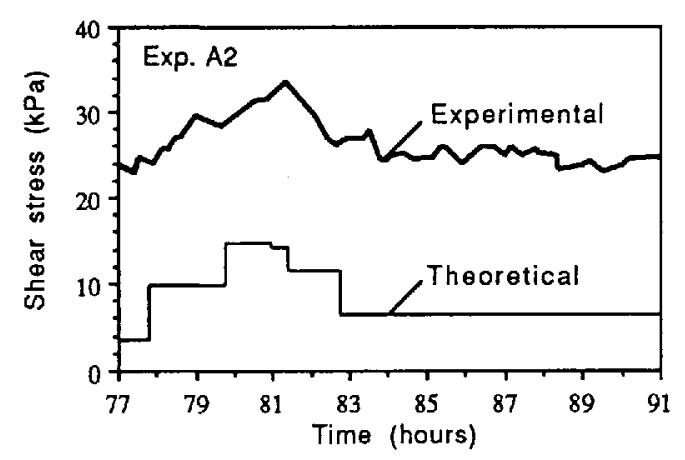

(b)

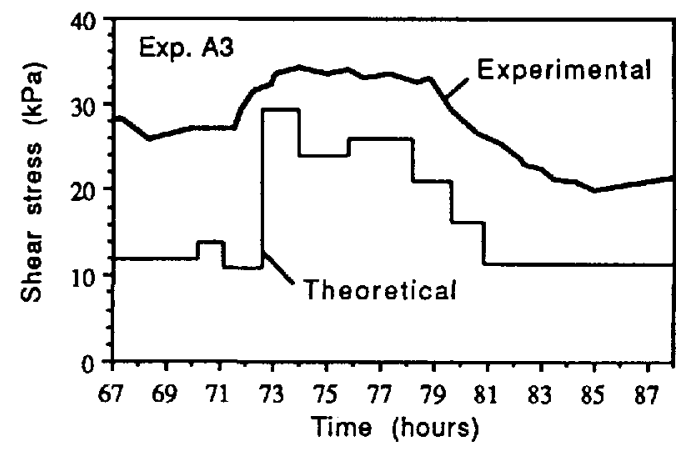

(c)

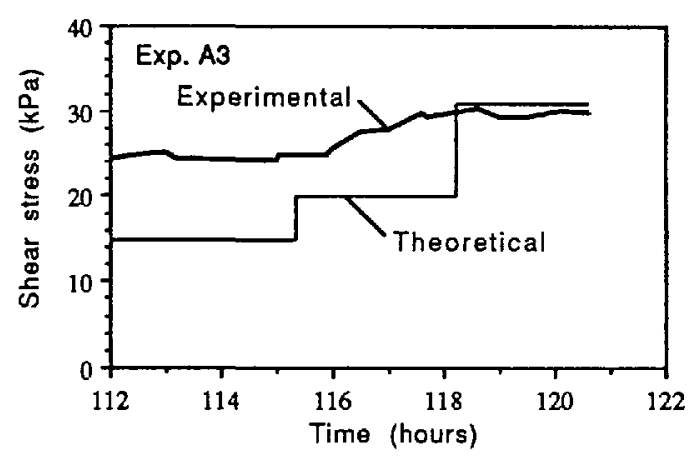

(d)

Fig. 10. Experimental and theoretical shear stress when the basal melt rate was raised temporarily in (a) experiment $A 2, N=5,(b)$ experiment $A 2, N=5$, and (c) experiment $A 3, N=5$, and (d) experiment $A 3, N=8 . \mu=0.7$ and $n=0.1 \mathrm{MPa}$. The shear stress due to ice-bed drag has been subtracted from the experimental shear stress.

velocity toward the bed $\left(1000 \mathrm{~mm} \mathrm{a}^{-1}\right)$ and $\mu$ (Hallet, 1981). Examination of bases of the ice blocks suggested that relative movement of fragments in the ice was small zompared to the bed displacement (Fig. 6). In both experiments, the shear stress exceeds the theoretical value by a factor ranging from 0 to 5 , which is roughly comparable to the theoretical underestimate of the drag force on the sphere in experiment SI (Fig. 8b). This may again suggest either that the water pressure in cavities beneath fragments was less than the expected pressure exerted by ice beneath fragments or that the effective ice viscosity was larger than $0.1 \mathrm{MPa}$ a. However, the theory overestimates by as much as a factor of three the magnitude of the increases in shear stress that resulted from the acceleration of basal melting. This inconsistency may indicate that the background shear stress was not steady during the experiments. One possibility is that, as basal melting was accelerated, the water film between the ice and the tablets thickened, resulting in decreases in ice-bed drag as some microscopic roughness elements on the tablets were submerged. Therefore, as melt rates were elevated and downward drag forces on rock fragments were increased, increases in fragment-bed friction may have been partially obscured by similtaneous decreases in ice-bed drag.

Differing rock-fragment concentrations were used in experiments $\mathrm{A} 2$ and $\mathrm{A} 3$. In experiment $\mathrm{A} 2$, fragments were isolated from each other by at least two fragment diameters, whereas in experiment $\mathrm{A} 3$ fragments were frozen in place with their edges in contact with each other. Philip (1980) analyzed regelation around a transverse array of cylinders and found that the force exerted on an individual cylinder in the array should significantly differ from the force on a single isolated cylinder. $\psi$ in Equation (5) was derived for an isolated sphere and thus may be a poor approximation in experiment A3. Figure $10 \mathrm{a}-\mathrm{d}$ indicates, however, that there were no gross differences in the downward drag force on rock fragments due to the different fragment spacing.

\section{Effects of ice pressure and fragment rotations}

At four times during the abrasion experiments, the pressure on the ice block was increased $0.2-0.5 \mathrm{MPa}$ and then held steady for periods of $7-30 \mathrm{~h}$. The vertical ice velocity and the shear stress during the periods of elevated ice pressure are shown in Figure $11 \mathrm{a}-\mathrm{d}$. The increase in pressure on the ice block resulted in high pressure-plate velocities that gradually declined with time. (An exception is at the end of experiment $A 2$, when the basal melt rate was raised by setting the heaters in the carriage warmer at hour 98 (Fig. 10d).) The large vertical ice velocities that occurred initially resulted in part from elastic compression of the ice. However, calculations using reasonable elastic constants (Northwood, 1947) suggest that elastic compression can account for maximum downward displacements of $0.01 \mathrm{~mm}$ or only about $1 \%$ of the observed initial displacements of the pressure plate. The remaining displacement is attributed to compression of air bubbles in the ice and thinning of the water film along the surface of the bed and fragments.

Increases in pressure on the ice block produced rapid increases in shear stress ranging from 1.0 to $6.2 \mathrm{kPa}$ (Fig. 11a-d). Increases in shear stress are expected due to thinning of the water film and resultant increases in ice-bed drag. A second possibility is that fragment-bed friction increased as a result of the higher ice pressure, consistent with the theory of Boulton $(1974,1979)$. The experimental increases in shear stress correspond to coefficients of friction ranging from 0.002 to 0.031 . Budd and others (1979) measured friction coefficients of 0.09 and 0.04 for clean temperate ice sliding over a smooth cement finish under normal loads of 1.0 and $3.0 \mathrm{MPa}$, respectively, Thus, increases in ice-bed drag may account for the observed increases in shear stress, although the possibility of small increases in fragment-bed friction cannot be precluded.

In experiments Al (Fig. 11a) and A3 (Fig. 11b), the initial rapid increases in shear stress were followed by periods when the shear stress rose more gradually. In Experiment Al, the shear stress generally increased until hour 103.6, although transient reductions occurred. Similarly, in experiment $A 3$ the shear stress rose until hour 102.4, the only exception being the decrease from hour 95 to 95.6 . A possible explanation for the gradual increases in shear stress is provided by the lengths and positions of striation segments, which suggest that fragments that rotated significantly began striating the bed after the increases in pressure. In experiment $\mathrm{Al}$, one of the two rock fragments that rotated during the experiment began striating the bed between hour 83.6 and 87.3 , which approximately coincides 


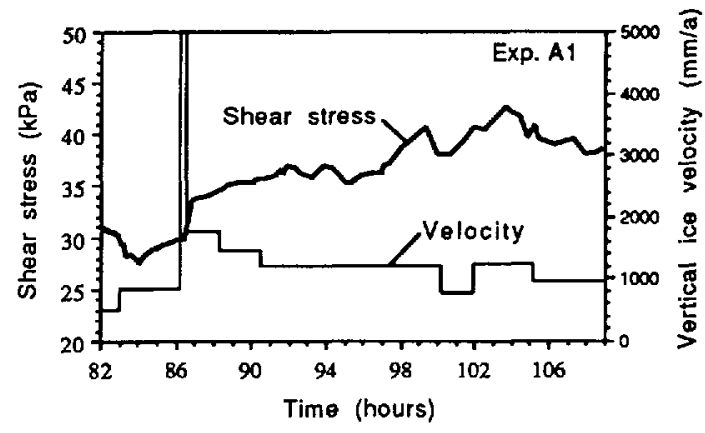

(a)

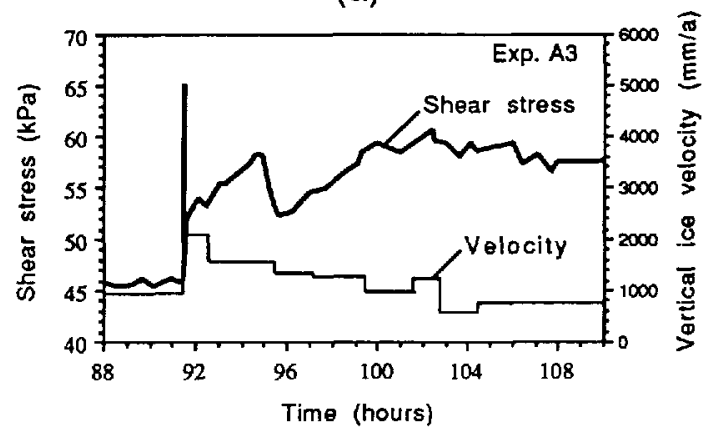

(b)

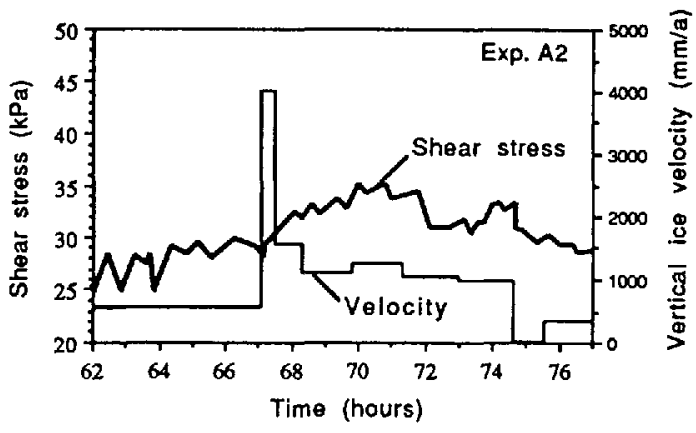

(c)

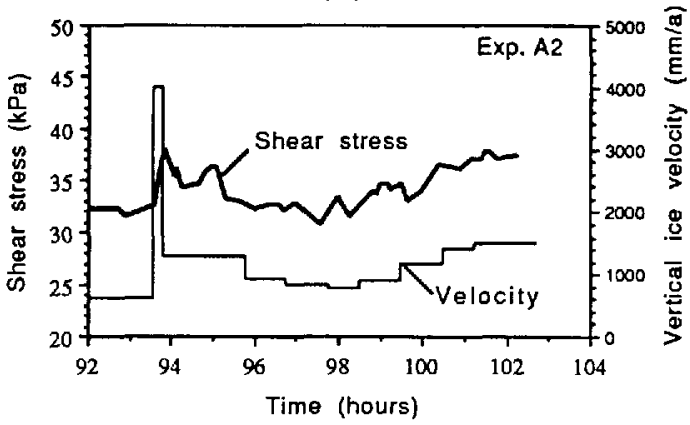

(d)

Fig. 11. Shear stress and vertical ice velocity when the pressure of the ice block was increased (a) $0.2 \mathrm{MPa}$ in experiment $\mathrm{AI}$ at hour 86.5. (b) $0.2 \mathrm{MPa}$ in experiment $\mathrm{A} 3$ at hour 9I.5, (c) $0.5 \mathrm{MPa}$ in experiment $A 2$ at hour 67.1 , and (d) $0.5 \mathrm{MPa}$ in experiment $A 2$ at hour 93.6. Note that increases in ice pressure in each experiment produce high velocities that decay thereafter while the ice pressure is sustained.

with the increase in ice pressure. This was determined by measuring the length of the last continuous segment of the striation it produced and again assuming that fragments moved at a velocity equal to $90-100 \%$ of the ice-sliding velocity. Ahead of this segment, the bed is not striated for about $3 \mathrm{~mm}$ before another ploughed groove is encountered. In experiment A3, the lengths of the final continuous segments of four striations that were ploughed by rotating rock fragments show that these fragments all began striating the bed after hour 92 and before hour 102.4. Thus, four of the five rock fragments that rotated in experiment A3 began striating the bed after the increase in ice pressure.

Twice in experiment A2 the normal load on the ice block was increased about $0.5 \mathrm{MPa}$ (Fig. $11 \mathrm{c}, \mathrm{d}$ ). Unlike the results of the other two experiments, initial increases in shear stress due to ice-bed drag were not followed by general increases in shear stress over the duration of the periods of elevated pressure. Only one fragment rotated in experiment A2. It produced two adjacent striations, each consisting of two continuous segments (Fig. 7c). The position of the break between segments suggests that the fragment quit striating the bed between hours 74.2 and 78.0 (Fig. 11c). The pressure on the ice block was reduced at hour 74.6; thus, during the period of elevated ice pressure from hour 67.0 to 74.6 the rock was apparently striating the bed, whereas shortly after the reduction in ice pressure the fragment quit abrading.

Therefore, in all the abrasion experiments, indirect evidence suggests that abrasion by fragments that rotated significantly was influenced by changes in ice pressure. Unlike fragments that rotated, those that did not rotate generally produced single continuous striations that did not change discernibly in width or depth over lengths that were being plowed when the ice pressure was increased. Thus, it is difficult to invoke increases in fragment-bed normal force to explain the initiation of abrasion by those fragments that rotated. An alternative explanation is that increases in ice pressure reduced the thickness of the water film around fragments, thereby increasing the drag between ice and microscopic roughness elements on fragment surfaces. Fragments encountering greater resistance to rotation should be more effective abrasive tools. Budd and others (1979) found experimentally that drag between clean temperate ice and rock surfaces increased with ice pressure, and experiments by Chadbourne and others (1975) have shown that small changes in water-film thickness $(<1.0 \mu \mathrm{m})$ may produce order-of-magnitude variations in the shear stress exerted by sliding ice on microscopically rough surfaces. Therefore, under low ice pressure, some fragments may have either rotated easily enough in the ice so that they could not scratch the bed, or as a result of rotating, temporarily lost contact with the bed. Under greater ice pressure, increased drag on fragment surfaces may have impeded rotations sufficiently to initiate the formation of continuous striation segments.

\section{DISCUSSION}

This study provides a means of empirically evaluating some of the postulates in theoretical models of glacial abrasion. In addition, it illuminates potentially important aspects of the process that are not included in these theories.

The results strongly support Hallet's (1979, 1981) hypothesis that the component of the ice velocity normal to the bed should be the primary influence on stresses beneath abrading rock fragments. Stresses beneath the sphere and rock fragments were closely linked to the downward ice velocity. In experiment $S 1$, the downward drag force on the sphere was generally within a factor of two of that predicted by linear regelation and creep theory, although the theoretical force is only approximate due to the poorly constrained effective ice viscosity in the vicinity of fragments. In the abrasion experiments, theoretical estimates of the shear stress due to fragment-bed friction were generally within a factor of five of experimental values.

The success of the theory is surprising in the light of the angularity of the rock fragments, the close packing of the fragments in experiment $A 3$, and particularly in the light of the fact that water, which was produced by melting along the sphere and fragment surfaces, collected in cavities beneath the sphere and fragments rather than refreezing as part of the regelation cycle. Refreezing was evidently inhibited by heat flow from the bed and to a lesser degree by heat generated as a result of friction along fragment-bed contacts. Apparently, heat transfer from the bed was sufficient to melt ice along the upper surface of the sphere and fragments at a rate roughly similar to that predicted by theory. Otherwise, the downward drag force on the sphere 
and fragments should have been significantly larger. Morris (1979) has shown analytically that cavities may form around clasts in transport in basal ice because the presence of the bed prohibits the classical regelation boundary conditions from being met around the whole of clast surfaces. She cautions, therefore, that a simple application of classical regelation and creep theory may not be adequate to calculate the forces exerted on a clast by flowing ice. The success of the classical theory when applied to these experiments suggests that the presence of water-filled cavities may not grossly alter the expected drag force on gravel-sized clasts.

An important element in the abrasion process that is ignored in abrasion models, as well as in subsequent formulations of debris-influenced sliding, is rock-fragment rotation. Despite numerous angularities along their surfaces, eight of the 16 rock fragments that were used in the abrasion experiments rotated in the ice more that $10^{\circ}$. Striations produced by these fragments were generally discontinuous. Some breaks between striation segments were small, suggesting that, as a fragment rotated, one striator point was lifted off the bed after a second point had made contact. Other breaks between striation segments exceeded the fragment diameter, indicating that for considerable lengths of time fragments either had rotated easily enough so that they could not exert sufficient shear stress on the bed to scratch it, or had temporarily lost contact with the bed by rotating. In either case, the ability of fragments to abrade and support shear stress may be strongly affected by fragment rotation, which should be closely related to fragment shape and surface roughness. For example, the average friction between relatively spherical rock fragments and the bed may be considerably less than the friction beneath more angular fragments. Fragment shape and surface roughness may therefore need to be incorporated into formulations of debris-influenced sliding.

Indirect evidence suggests that fragment rotations were influenced by changes in ice pressure. Increases in ice pressure may have reduced the thickness of the water film around fragments, resulting in increased drag on fragment surfaces and greater resistance to fragment rotation. Assuming laminar flow, the thickness of the water film should be inversely related to the cubed root of the pressure gradient driving a given water discharge (Batchelor, 1967 , p. 183). It is likely, as a result of leakage from around the rock tablets, that higher ice pressure increased water-pressure gradients along fragment surfaces, thereby thinning the melt film adjacent to fragments. Thus, the apparent effect of ice pressure on fragment rotations may only be applicable in areas of glacier beds with drainage conditions similar to those in the experiments. For example, if in the lee of a bedrock bump a cavity exists at atmospheric pressure, the rotation of abrading fragments may be impeded by the elevated ice pressure along the bump's stoss surface. As suggested by a reviewer, in future experiments some fragments will be positioned near the edges of the ice block to explore the effects of pressure variations in the water film on fragment rotations and

\section{CONCLUSIONS}

Abrasion of a planar bedrock surface by a temperate glacier has been closely simulated, and some of the important variables in the pracess have been measured. Striations similar to those observed on glaciated bedrock were produced at a typical sliding velocity for temperate glaciers and at realistic basal melt rates and ice pressures. The ice near the bed and near the surfaces of abrading rock fragments was at the pressure-melting temperature.

The principal results of these experiments may be summarized as follows. (1) Consistent with the theory of Hallet $(1979,1981$, paper in preparation), ice flow towards glacier beds strongly influences stresses beneath abrading rock fragments and thus plays an important role in controlling the rate of abrasion and the shear stress supported by a given concentration of basal debris. (2) Classical regelation and creep theory provides an approximate estimate of the drag force on some small rock fragments, despite the numerous assumptions and uncertainties inherent in the theory and its application to glacial abrasion. (3) Rock fragments in contact with the bed may rotate frequently, limiting their ability to striate the bed and the shear stress they support. (4) Depending upon the local water drainage, variations in ice pressure at the bed may influence fragment rotations.

\section{ACKNOWLEDGEMENTS}

I am indebted to $R$. Hooke for providing me with the experimental apparatus and for valuable guidance while these experiments were conducted. B. Hallet provided helpful advice throughout the course of this study and his critical comments significantly improved the paper. His experiment with an instrumented trailer hitch at the base of Bondhusbreen in 1982 provided stimulus for the experiments with the concrete sphere. R. Bohm and J. Marvin helped solve numerous experimental problems. I also thank $R$. Hooke, P. Hudleston, H. Wright, and W. Gerberich for reviewing a preliminary version of this paper as a section of my doctoral thesis at the University of Minnesota.

\section{REFERENCES}

Anderson, R.S., B. Hallet, J. Walder, and B.F. Aubry. 1982. Observations in a cavity beneath Grinnell Glacier. Earth Surface Processes and Landforms, 7(1), 63-70.

Batchelor, G.K. 1967. An introduction to fluid dynamics. Cambridge, Cambridge University Press.

Boulton, G.S. 1974. Processes and patterns of glacial erosion. In Coates, D.R., ed. Glacial geomorphology. Binghamton, NY, State University of New York, 41-87.

Boulton, G.S. 1979. Processes of glacier erosion on different substrata. J. Glaciol., 23(89), 15-38.

Boulton, G.S., E.M. Morris, A.A. Armstrong, and A. Thomas. 1979. Direct measurement of stress at the base of a glacier. J. Glaciol., 22(86), 3-24.

Budd, W.F., P.L. Keage, and N.A. Blundy. 1979. Empirical studies of ice sliding. J. Glaciol., 23(89), 157-170.

Carol, H. 1947. The formation of roches moutonnées. $J$. Glaciol., 1(2), 57-59.

Chadbourne, B.D., R.M. Cole, S. Tootill, and M.E.R. Walford. 1975. The movement of melting ice over rough surfaces. J. Glaciol., 14(71), 287-292.

Chamberlin, T.C. 1888. The rock scourings of the great ice invasions. U.S. Geol. Surv. Annu. Rep. 7, 155-248.

Drake, L.D. and R.L. Shreve. 1973. Pressure melting and regelation of ice by round wires. Proc. $R$. Soc. London, Ser. A., 332(1588), 51-83.

Drewry, D. 1986. Glacial geologic processes. London, Edward Arnold.

Duval, P. 1977. The role of the water content on the creep rate of polycrystalline ice. International Association of Hydrological Sciences Publication 118 (Symposium at Grenoble 1975 - Isotopes and Impurities in Snow and Ice), 29-33.

Gilbert, G.K. 1910. Harriman Alaska Series. Vol. 3. Glaciers and glaciation. Washington, DC, Smithsonian Institution.

Hallet, B. 1979. A theoretical model of glacial abrasion. $J$. Glaciol., 23(89), 39-50.

Hallet, B. 1981. Glacial abrasion and sliding: their dependence on the debris concentration in basal ice. Ann. Glaciol., 2, 23-28.

Harrison, W.D. 1972. Temperature of a temperate glacier. $J$. Glaciol., 11(61), 15-29.

Hooke, R. LeB. 1984. On the role of mechanical energy in maintaining subglacial water conduits at atmospheric pressure. J. Glaciol., 30(105), 180-187.

Hooke, R. LeB, and N.R. Iverson. 1985. Experimental study of ice flow around a bump: comparison with theory. Geogr. Ann., 67A(3-4), 187-197.

Iverson, N.R. Unpublished. Theoretical and experimental analyses of glacial abrasion and quarrying. (Ph.D. thesis, University of Minnesota, 1989.)

Jaeger, J.C. and N.G.W. Cook. 1979. Fundamentals of rock mechanics. New York, Chapman and Hall.

Lister, H., A. Pendlington, and J. Chorlton. 1968. Laboratory experiments on abrasion of sandstones by ice. International Association of Scientific Hydrology 
Publication 79 (General Assembly of Bern 1967 - Snow and Ice), 98-106.

Lliboutry, L. and P. Duval. 1985. Various isotropic and anisotropic ices found in glaciers and polar ice caps and their corresponding rheologies. Annales Geophysicae, 3(2), 207-224

McCall, J.G. 1960. The flow characteristics of a cirque glacier and their effect on glacial structure and cirque formation. In Lewis, W.V., ed. Investigations on Norwegian cirque glaciers. London, Royal Geographical Society, 39-62. (R.G.S. Research Series 4.)

Mathews, W.H. 1979. Simulated glacial abrasion. J. Glaciol., 23(89), 51-56.

Morgan, V.I. 1979. A system for accurate temperature control in small fluid baths. J. Glaciol., 22(87), 389-391.

Morris, E.M. 1979. The flow of ice, treated as a Newtonian viscous liquid, around a cylindrical object near the bed of a glacier. J. Glaciol., 23(89), 117-129.

Northwood, T.D. 1947. Sonic determination of the elastic properties of ice. Can. J. Res., 25(2), 8-95.

Philip, J.R. 1980. Thermal fields during regelation. Cold Reg. Sci. Technol., 3(2-3), 193-203.

Röthlisberger, H. 1968. Erosive processes which are likely to accentuate or reduce the bottom relief of valley glaciers. International Association of Scientific Hydrology Publication 79 (General Assembly of Bern 1967 - Snow and Ice), 87-97.

Scholz, C.H. and J.T. Engelder. 1976. The role of asperity indentation and ploughing in rock friction. I. Int. J. Rock Mech. Min. Sci. Geomech. Abstr., 13, 149-154.

Shoemaker, E.M. 1986. Debris-influenced sliding laws and basal debris balance. J. Glaciol., 32(111), 224-231.

Shoemaker, E.M. 1988. On the formulation of basal debris drag for the case of sparse debris. J. Glaciol., 34(118), 259-264.

Watts, P.A. Unpublished. Inclusions in ice. (Ph.D. thesis, University of Bristol, 1974.)

Wolf, H. 1983. Heat transfer. New York, Harper and Row. 